\title{
Genetic diversity of ranch and feral American mink (Neovison vison Schreber, 1777) in Poland in relation to the natural population of the species
}

\author{
Beata Horecka \\ Institute of Biological Bases of Animal Production, Sub-Department of General and Molecular \\ Genetics, Faculty of Biology, Animal Sciences and Bioeconomy, University of Life Sciences in \\ Lublin, Akademicka 13 Street, 20-950 Lublin, Poland. \\ Email: beata.horecka@up.lublin.pl
}

\begin{abstract}
In Poland, the number of feral mink (Neovison vison) and the size of the fur-farming industry are growing. There is a concern that the gene pool of the wild living mink is being infiltrated by that of ranch animals. Three populations were analyzed: Polish ranch mink, feral animals from Poland, and, they were for the first time in Poland, compared with wild individuals from North America. The breeding history of the species and the main ways of introducing the American mink into new areas on different continents were considered. The final research included analysis of the polymorphism of 12 Mustelidae-specific microsatellite loci. It showed a similar level of genetic diversity in all the investigated populations. The research revealed the existence of geographically-specific subpopulations of feral mink in Poland, characterized by different origins, and indicated a small degree of introgression between Polish ranch and wild living populations in the past although the assignment simulation makes it clear that they are genetically distinct groups. The results are in accordance with previously reported models of colonization of Poland by this species and help to explain the influence of anthropogenic factors on the current status of this invasive species. Mixing of two separate genetic pools from the native range in Poland is a newly identified factor, shaping the genetic structure of ranch and feral populations of Neovison vison.
\end{abstract}

Keywords. Microsatellites, ranch mink, invasive species, American mink, Neovison vison.

HoReCKA B. (2019). Genetic diversity of ranch and feral American mink (Neovison vison Schreber, 1777) in Poland in relation to the natural population of the species. Belgian Journal of Zoology 149 (1): 49-61. https://doi.org/10.26496/bjz.2019.30

\section{Introduction}

Populations of introduced species derived from a small number of founders usually suffer adverse effects of low genetic variation that may limit their adaptability to new conditions encountered in the colonized environment (DLUGOSCH \& PARKER 2008). However, there is also a phenomenon of the so-called genetic paradox (FRANKHAM 2005) relating to invasive species, which is associated with overcoming the adverse impact of the introduction (low genetic variability, low evolutionary potential) of populations affected by the bottleneck effect. If the introduction occurs in many places in the area and the individuals forming the invasive populations come from different areas of their native range of occurrence, the gene flow between these populations creates zones of high genetic diversity, and the individuals that inhabit them are characterized by very good viability (CRAWFORD \& WHITNEY 2010). 
The American mink (Neovison vison) is a species that appeared natively only in North America. The spread of the wild American mink outside its natural area of distribution occurred at different places and at different times and was associated with accidental escapes and deliberate releases. There were at least four ways to introduce this species into new areas: intentional introductions aimed at creating game populations of fur animals in the area of the former Soviet Union (HERMAN 1979), deliberate release of ranch animals related to animal rights movements (REYNOLDS et al. 2004), devastation of farms during World War II (SŁAWOŃ 1978; KRUSKA \& SiDOROVICH 2003), and accidental escapes of individuals from farms (KALETA 1984; HAMMERSHØJ et al. 2005; ZALEWSKI et al. 2010). Taking into consideration the increased intraspecific diversity of ranch individuals, particular founders are likely to differ from each other genetically and anatomically. Farm animals are represented by a wide range of colour varieties, differing in body size (NES et al. 1988; JAKUBCZAK 2006a, 2006b). Therefore, the present-day differences between populations reflect different origins of the founding individuals, rather than appearing to represent actual subspecies (KRUSKA \& SIDOROVICH 2003). Individuals originating from farms gave rise to wild populations reproducing in the wild. In countries with a well-developed fur farming industry the risk of escapes is considered to be higher, and an extreme example might be Denmark, where simulation studies indicated that the number of feral of mink is sustained by regular supplements from mink farms and that no true feral population exists (PERTOLDI et al. 2013).

In Poland, in the first years of its presence, the most intensive growth in the number of American mink was found in the north-eastern area (BRZEZIŃSKI \& MARZEC 2003). Due to previously mentioned introductions in the former USSR, animals observed in north-eastern Poland were considered as migrants from the eastern border. On the other hand, a significant majority of breeding farms are located in the north-western region of the country (JEŻEWSKA-WITKOWSKA et al. 2014). Thus, it is assumed that individuals that had escaped from breeding farms were the basic group of founders for feral American mink populations living in this area (BRZEZIŃSKI \& MARZEC 2003; ZALEWSKI et al. 2010). In this aspect, one of the possible explanations of the explosive demographic growth rate in feral mink populations might be the heterosis effect of crosses between individuals from different ranch colour lines, even if their number was rather limited (THIRSTRUP et al. 2014). Comparative studies carried out so far indicate significant differences in phenotypic and genetic traits not only between animals kept on farms and their wild ancestors, but also between those derived from the first group of feral populations living in the wild in the areas outside the natural range of the species (LYNCH \& HAYDEN 1995; BELLIVEAU et al. 1999; KRUSKA \& SCHREIBER 1999; KRUSKA \& SIDOROVICH 2003; KIDD et al. 2009; TAMLIN et al. 2009; BOWMAN et al. 2012; THIRSTRUP et al. 2015). This suggests that three categories of American mink should be distinguished: wild mink, which includes only the native populations living in the areas of North America; ranch mink, i.e., animals kept on farms and being the subject of breeding (selection), and feral mink, including populations of animals that live in the wild outside the natural area of the occurrence. In the case of the Eastern European feral populations, the populations of individuals released in the former Soviet Union should mainly be taken into account, including individuals that escaped from farms, mostly in the first years of breeding. The aim of the study was to determine the level of genetic diversity within populations of ranch and wild living American mink, taking into account the native and introduced populations. Ranch and feral populations from Poland were already investigated in terms of their genetic diversity, but in this study they are for the first time compared with native wild mink. Analysis of the relationships and evaluation of the fixed differences between these three mink groups may help to explain the origin and predict the invasive potential of feral populations.

\section{Material and methods}

The research was carried out with the approval of the II Local Ethical Committee for animal experiments in Lublin (Resolution No. 83/2009). The studies included ranch mink of the standard colour type, both males and females, in the first year of their life. Samples were taken from unrelated animals from one farm (100 individuals). Second group included 39 feral animals, representing both sexes and belonging 
HORECKA B., American mink genetic diversity studies

to two subpopulations: from the area of north-eastern (NE) Poland (near Olsztyn - 24 individuals) and north-western (NW) Poland (around Drawsko Pomorskie - 15 individuals). Two individuals came from road traffic accidents while the rest were obtained in cooperation with Polish Hunting Association. Obtained material was immediately put in $-4^{\circ} \mathrm{C}$. Third group included 50 wild-living animals from North America, whose skins were purchased on an auction in Canada in 2011. Unfortunately, the specific region of their origin was not known. Conserved skins were kept in dry conditions and biological samples were taken immediately on receipt to the laboratory. In the case of the ranch animals, whole peripheral blood was collected to vacuum tubes containing EDTA. Fragments of skin with hair were the material from the wild living animals from Poland and North America. DNA extraction was performed using a DNeasy Blood and Tissue Kit (QIAGEN). The purity and concentration of the isolated DNA was assessed by spectrophotometry (BioPhotometer, Eppendorf) and electrophoretic separation on a 1\% agarose gel containing ethidium bromide in $1 \times \mathrm{TBE}$ buffer, with voltage $70 \mathrm{~V}$ for 40 minutes. The samples were visualized under UV light and archived using the ScionImage program.

On the basis of the literature, 17 microsatellite markers specific to the Mustelidae family were selected for the analyses: Mvi1302, Mvi1321, Mvi1341, Mvi1354, Mvi1843, Mvi2243, Mvi1273 (VINCENT et al. 2003), Mvi4006, Mvi4054, Mvi4031, Mvi4052, Mvi4055, Mvi4066, Mvi5001 (ANistoroAeI et al. 2006), Mer022 (Fleming et al. 1999), Mvi4049 (ANISTOROAEI et al. 2007), and Mvi804 (FARID et al. 2004). Fifteen microsatellite sequences were set in four multiplexes: I - Mvi1341, Mvi1354, Mvi4055, Mvi4066, Mer022; II - Mvi1302, Mvi1321, Mvi1843, Mvi4054, Mvi5001; III - Mvi2243, Mvi4031, Mvi4052; IV -Mvi804, Mvi1273. For two microsatellite markers (Mvi4006, Mvi4049), PCR was performed individually. The reaction mixture was prepared using AmpliTaq Gold 360 DNA Polymerase (ThermoFisher Scientific). The basic composition of the PCR mix was the same for all reactions. Each sample contained $2 \mu \mathrm{l}$ of genomic DNA, 1x reaction buffer (supplied with the polymerase), $10 \%(\mathrm{v} / \mathrm{v})$ of G/C buffer, $2 \mathrm{mM} \mathrm{MgCl}$, and $0.2 \mathrm{mM}$ of each dNTP. The individual PCR reactions varied by the amount of primers (the amount of each primer per sample) - for the sequences: Mvi1341, Mvi1354, Mvi4055, Mvi1321, Mvi4054 - 0.5 M; Mvi5001, Mvi804, Mvi1273, Mvi4049, Mvi4006 - $0.2 \mu \mathrm{M}$; Mvi4066, Mer022, Mvi1302, Mvi1843,Mvi2243, Mvi4031, Mvi4052-0.1 $\mu \mathrm{M}$. The following amounts of polymerase were added: multiplex I and II - $0.5 \mathrm{U} /$ sample; multiplex III, IV, and microsatellite sequences amplified individually $-0.2 \mathrm{U} / \mathrm{sample}$. The total volume of a single sample was $10 \mu 1$. Amplification was performed using Labcycler (SensoQuest). The thermal profiles were as follows: initial denaturation at $95^{\circ} \mathrm{C}$ for $10 \mathrm{~min}$. followed by 35 cycles - denaturation at $95^{\circ} \mathrm{C}$ for $30 \mathrm{~s}$, annealing at $56^{\circ} \mathrm{C}$ for Mvi4006, $60^{\circ} \mathrm{C}$ for multiplex I, II, IV, $63^{\circ} \mathrm{C}$ for multiplex III and Mvi4049 for $60 \mathrm{~s}$, extension at $72^{\circ} \mathrm{C}$ for $60 \mathrm{~s}$, at the end followed by a final extension of $72^{\circ} \mathrm{C}$ for $10 \mathrm{~min}$. Separation of products was performed using an ABI Prism 3100-Avant Genetic Analyzer in a 4\% polyacrylamide gel (POP-4). 3100 - Avant ABI Prism - Data Collection and Gene Mapper v. 3.5 software was used to collect the results and analyze the length of separated fragments. The length of alleles was determined in relation to the internal size standard GeneScan - 500 ROX.

The number and frequency of alleles at a given locus $\left(\mathrm{N}_{\mathrm{A}}\right)$, effective number of alleles $\left(\mathrm{N}_{\mathrm{E}}\right)$, and observed $\left(\mathrm{H}_{\mathrm{O}}\right)$ and expected $\left(\mathrm{H}_{\mathrm{E}}\right)$ heterozygosity were calculated separately for each population and Hardy-Weinberg disequilibrium significance was checked. The effective number of alleles $\left(\mathrm{N}_{\mathrm{E}}\right)$ determines the number of alleles required to provide the same heterozygosity as the actual number of alleles, in cases when they are all present with the same frequency (KIMURA \& CROW 1964). This measure is used frequently because it is less sensitive to sample size and the presence of rare alleles (FRANKHAM 1996). For each population, the inbreeding coefficient $\left(\mathrm{F}_{\mathrm{IS}}\right)$ and the frequencies of null alleles were determined. Polymorphic information content (PIC) values were estimated for each of the loci separately. The calculations were performed using the program Cervus ver. 3.0.3 (KALINOWSKI et al. 2007) and POPGENE ver. 1.31 (YEH \& BOYLE 1997). Evaluation of the presence of cryptic genetic structure between the wild, feral, and ranch American mink was carried out using STRUCTURE 2.3.3 (PRITCHARD et al. 2000). The analysis in STRUCTURE contained previously fixed information about 
the assignment of an individual to a specific population. A mixed-parameter model with correlated allele frequencies was used with the "burn-in" phase of 5000 iterations, followed by 50000 MCMC (Markov Chain Monte Carlo) replication phase. The subsequent probability values for the number of populations $(\mathrm{K})$ in the range from 1 to 10 were calculated from 20 independent simulations to determine regularity. The highest value of the index of likelihood function changes in relation to $K(\Delta K)$ was used to find the most likely number of K (EVANNO et al. 2005). This parameter was determined using STRUCTURE HARVESTER (EARL \& VONHOLDT 2012). The research was focused on determining further genetic structuring of the three investigated groups, therefore in the final analysis, $\mathrm{K}$ values from 3 to 10 were taken into account in the $\Delta \mathrm{K}$ estimation.

\section{Results}

All the analyzed loci were checked for the presence of possible null alleles. Estimation of the frequency of these alleles was carried out separately for each population. Loci characterized by a frequency of null alleles higher than 0.1 in at least two populations were excluded from further analysis. These were loci Mvi1302, Mvi1354, Mvi4055, Mvi4052, and Mvi4006.

Private alleles were reported for each population; however, they were characterized by low frequencies, especially in the case of alleles specific for the ranch mink population $(0.48 \%-1.04 \%)$. The greatest number of private alleles (nine) was observed in the group of wild mink from North America, and their frequencies ranged from $1.00 \%$ to $7.14 \%$. In the populations of the Polish feral mink, three specific alleles were noted with frequencies ranging from $1.32 \%$ to $5.71 \%$. Based on the analysis of polymorphism of 12 loci, basic parameters describing the genetic variability of the studied populations were calculated (Supplementary Table 1). The analyzed loci were characterized by high informativeness reflected by the values of PIC, which in almost all cases exceeded 0.5. Loci Mvi4049 in the ranch population (PIC $=0.40)$ and Mvi4054 in the wild North American mink population $(\mathrm{PIC}=0.34)$ were exceptions; both loci were moderately informative.

The average number of alleles per locus $\left(\mathrm{N}_{\mathrm{A}}\right)$ in both feral mink groups was higher than 5 , whereas this value in the wild and ranch mink was greater than 8 . In these groups, the effective number of alleles $\left(\mathrm{N}_{\mathrm{E}}\right)$ was approximately two-fold lower than the observed number of alleles, and the $\mathrm{N}_{\mathrm{E}}$ value in the ranch mink was slightly lower than that in the wild mink (3.87 vs 4.29). Five loci in the ranch mink group and three loci in the wild mink significantly deviated from Hardy-Weinberg equilibrium. In the case of both feral subpopulations, this was observed in one locus in the eastern population and in two loci in the case of individuals from the west (Supplementary Table 1). The mean $\mathrm{H}_{\mathrm{E}}$ of all the mink groups was almost the same, ranging from 0.69 to 0.73 . In the ranch mink group, the mean value of the inbreeding coefficient $\left(\mathrm{F}_{\mathrm{IS}}\right)$ was -0.03 , and a negative value of this coefficient was also observed in the

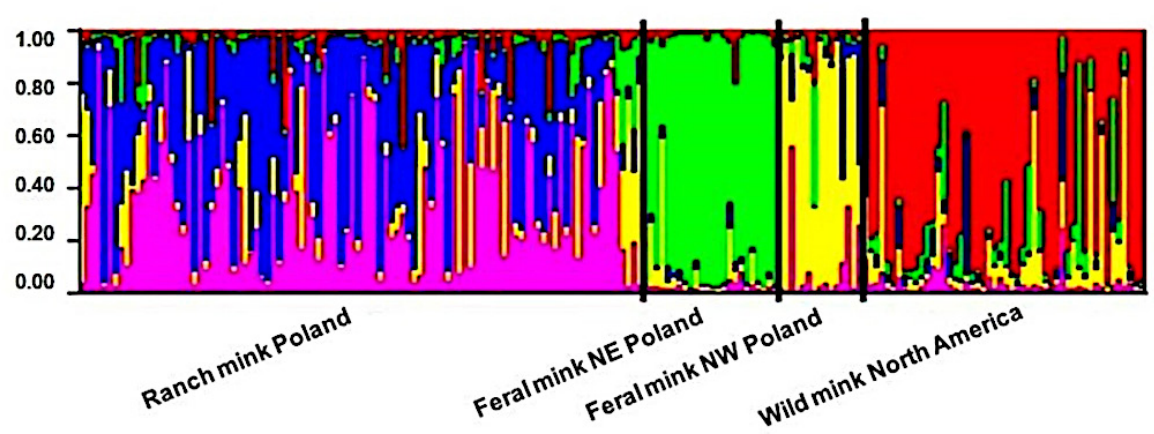

Fig. 1 - Bar-plot generated in STRUCTURE assuming membership of American mink individuals into five genetic pools, according to the estimated value of $K=5$. Separate populations are marked below the plot. 
HORECKA B., American mink genetic diversity studies

\section{TABLE 1}

Average proportion of membership (q) of analyzed American mink individuals in the five most probable genetic pools. The highest percentage for each cluster is marked by *.

\begin{tabular}{ccccccc}
\hline Origin & n & \multicolumn{5}{c}{ Estimated number of clusters } \\
\hline & & 1 & 2 & 3 & 4 & 5 \\
wild mink North America & 50 & $0.691^{*}$ & 0.085 & 0.055 & 0.129 & 0.040 \\
feral mink NE Poland & 24 & 0.030 & $0.858^{*}$ & 0.024 & 0.066 & 0.021 \\
feral mink NW Poland & 15 & 0.042 & 0.060 & 0.100 & $0.694^{*}$ & 0.105 \\
ranch mink Poland & 100 & 0.047 & 0.040 & $0.382^{*}$ & 0.129 & $0.401^{*}$ \\
\hline
\end{tabular}

eastern feral mink subpopulation $\left(\mathrm{F}_{\text {IS }}=-0.10\right)$. An opposite situation was found for the wild mink from North America, where the $\mathrm{F}_{\text {IS }}$ value was 0.10 , and in the feral population from western Poland $\left(\mathrm{F}_{\text {IS }}=\right.$ 0.06). The Bayesian method was used to separate genetically distinct groups. Calculation of $\mathrm{K}$ from the output of STRUCTURE produced a modal value of this parameter at $\mathrm{K}=5$ (Supplementary Table 2 and Supplementary Fig. 1). The five clusters of genotypes corresponded to (1) wild mink from North America, (2) feral mink from north-eastern Poland, (3 and 5) ranch mink, and (4) feral mink from northwestern Poland (Table 1 and Fig. 1). This result showed that there are distinct groups of wild, ranch, and feral mink. The ranch mink formed the most heterogeneous group. The ranch animals were assigned to two clusters ( 3 and 5), although the individual animals were characterized by a different proportion of these two genetic pools (Table 1). Relevant information about the genetic structure was obtained in the case of the wild- living mink from Poland. In general, the population was assigned to two genetic pools (clusters 2 and 4). In cluster 2, there were up to $61.5 \%$ of the population of feral mink. In contrast, $30.8 \%$ of animals of this group were assigned within the second cluster. Three individuals from the Polish feral population, with the total value of $q$ for clusters 3 and 5 of: $0.667,0.736$, and 0.737 , were classified as representatives of the ranch population.

The biological samples derived from the feral animals were obtained from two different locations (northeastern and north-western Poland). The analyses of the assignment of the animals in STRUCTURE showed a perfect correlation between the region of their occurrence and the membership in a particular cluster. All the American mink from the area near Olsztyn are classified within cluster 2, while almost all the specimens collected in the area of Drawsko Pomorskie were included in cluster 4. Individuals from this group of mink that were assigned to the ranch population, as previously noted, were exceptions.

Based on the differences in the frequencies of microsatellite alleles between the clusters (calculated in STRUCTURE as net nucleotide distance), the UPGMA tree was drawn, including five genetic groups (Fig. 2). It can be seen that the feral animals from north-western Poland were grouped together with the ranch mink individuals. The ranch animal group was represented by two branches according to the presence of two genetic pools in their genotypes. The feral mink population from north-eastern Poland was placed within the second clade together with the wild mink population from North America.

\section{Discussion}

Originating from North America, American mink became a common species, but it's distribution outside the native range was connected with many factors that shaped the genetic structure and the level of diversity of particular populations. Coexistence of ranch and feral mink populations takes place in many European countries and raises controversy because of the invasive potential of the species. Comparison of Polish ranch and feral populations with wild animals from North America, serving as a standard, clarified the origin of feral individuals and showed pronounced genetic distinctiveness of the investigated populations and sub-populations. 


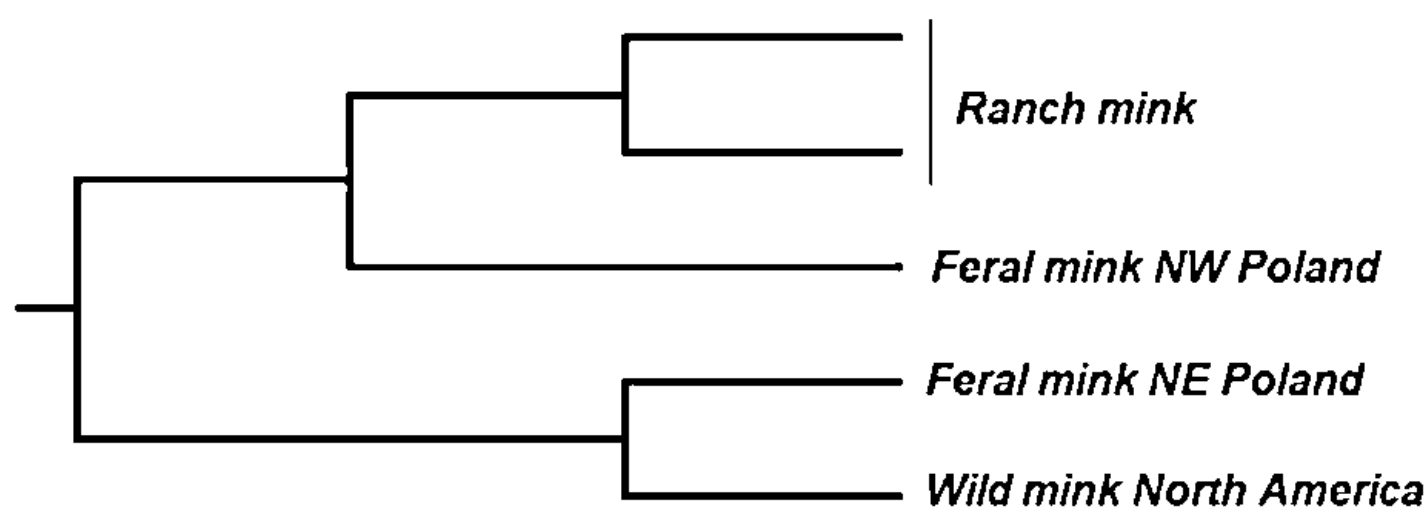

Fig. 2 - UPGMA tree presenting the phylogenetic relationships between American mink populations, according to the cluster division generated in STRUCTURE based on the frequency of microsatellite alleles.

The average number of alleles recorded in this study was lower than that reported by MICHALSKAPARDA et al. (2009) and ZALEWSKI et al. (2010) for the Polish ranch mink and feral populations. This may have resulted both from these authors analyzing a greater proportion of the population and from the fact that the ranch mink group included individuals of different colour varieties, which undoubtedly contributed to the genetic diversity of the population (JAKUBCZAK et al. 2011). The effective number of alleles estimated in my study (both the average and for an individual locus) was significantly lower than the observed number, which was also found by MICHALSKA-PARDA et al. (2009). Significant differences were found in the observed and expected heterozygosity. The different values of these parameters for the ranch mink result from many factors. The level of heterozygosity in the case of fur animals depends, among other factors, on the colour variety. Determination of the level of heterozygosity for several varieties together can contribute to its increased value due to the occurrence of private alleles for different colour varieties of fur animals (CIEŚLAK et al. 2011; JAKUBCZAK et al. 2011). In addition, the level of heterozygosity of ranch populations also results from the mating system and the intensity of artificial selection. Similar dependence was found in Polish ranch populations by MiCHALSKAPARDA et al. (2009) and in native Canadian mink populations by BELliVEAU et al. (1999), KIDD et al. (2009) and BEAUCLERC et al. (2013). It must be assumed that the high level of heterozygosity of native populations in North America could be affected by the presence of as many as 15 subspecies of the American mink on the continent. Current studies indicate occurrence of two mitochondrial lineages of the American mink in its native range (eastern and western clade) (GARCíA et al. 2017). Mixing of these two lineages may increase the level of genetic diversity of this population. But it also has influence on other mink populations, as they all originate from North American individuals. Then, it may also explain the share of two different genetic pools, evaluated by the assignment analysis, in the ranch mink genotypes analyzed in this study. Animals caught in the native range and then used for fur farming probably represent a mixture of both North American clades.

The inbreeding coefficient $\left(\mathrm{F}_{\text {IS }}\right)$ evaluated in this study may indicate no clear internal genetic structure within the group of mink of the standard colour type, while the value measured by MICHALSKA-PARDA et al. (2009) probably results from the inclusion of mink belonging to different colour varieties in one tested group and the presence of a pronounced genetic structure. Selection, controlled mating and exchange of animals between farms to avoid inbreeding are probably the main factors influencing the excess in the proportion of heterozygotes in the case of ranch animals. In the case of the groups of wildliving animals, the excess may be correlated with the existence of subpopulations and the associated Wahlund effect consisting in erroneous assignment of samples taken from separate subpopulations to the same group, and thus recording a seeming excess of heterozygotes. This is also confirmed by the results published by ZALEWSKI et al. (2010), where the north-eastern and north-western Polish populations 
HORECKA B., American mink genetic diversity studies

analyzed separately exhibited a relatively low value of $\mathrm{F}_{\mathrm{IS}}$, demonstrating their high genetic diversity as well as genetic homogeneity (understood as specific frequency of alleles of particular sub-populations) and possibly reflecting their distinctiveness. However, the inbreeding coefficient value studied by ZALEWSKI et al. (2010) for feral mink from central Poland was higher, which might be associated with the occurrence of contact areas between eastern and western populations and, therefore, assignment of individuals from these two subpopulations within one group as the case of Wahlund effect. According to ZALEWSKI \& BRZEZIŃSKI (2014), the genetic structure of introduced populations depends on two basic factors, i.e., the genotypic diversity of individuals that have established the populations and the presence of barriers limiting the environmental dispersion of individuals and communication between the newly established populations. It is therefore determined by both past processes and those occurring after the animals are introduced into the new environment (THISTRUP et al. 2015). The division of the feral animals from Poland into two distinct genetic groups results from mixing of genetically different subpopulations of the American mink in the environment. Similar relationships were demonstrated by ZALEWSKI et al. (2010). However, the use in this study of North American individuals as a kind of reference group for the species, allowed clarification of the origin of these subpopulations. It is known that invasive species often show a well-developed genetic structure in newly inhabited areas, which is sometimes better differentiated than in native populations (MARRS et al. 2008). The results obtained by ZALEWSKI et al. (2010) indicate that the eastern and western Poland regions were inhabited by American mink via different processes. One of them was the influx of feral animals from the eastern border, and specifically from Belarus. This is in agreement with the observations of the appearance of the American mink in Poland. These animals then spread to the west and south of the country. However, this model proved to be suitable only for the eastern areas of the country. Feral individuals from the Polish northeastern population were characterized by a more clearly marked genetic distinctiveness in relation to ranch mink than animals belonging to the population from the northwest. In turn, their remarkable similarity to individuals natively inhabiting North America was found (Fig. 2). This confirms the model of settlement of eastern Poland by Neovison vison individuals discussed above. The American mink inhabiting this part of the country are derived from a population of feral animals released on the territory of the former USSR. Although they were kept on breeding farms, the time they have been subjected to the process of domestication was relatively short. This enabled them to maintain many features of their ancestors and it can be seen in the results of this study, as the feral mink population from north-eastern Poland was placed within the second clade together with the wild mink population from North America. However, breeding procedures, such as selection or the mating system, even if they were practiced for only a short time, led to the development of some differences, including genetic changes. In addition, when released into the natural ecosystems, these individuals were under the influence of environmental factors that have an impact on creation of mechanisms of adaptation or selection of better-adapted organisms. Under the influence of these two major factors, the population of feral mink developed genetic distinctiveness in relation to the ranch population, while maintaining a high degree of similarity to the wild mink from North America. In turn, the western areas of Poland were probably inhabited by the American mink in a different way, i.e., as a result of colonization by individuals that are descendants of escapees from farms. This theory is reflected in the data from the present study. It must be concluded that the ranch animal escapes leading to the creation of feral populations in north-western Poland took place in the distant past, as it was also previously mentioned by THISTRUP et al. (2015). The escapes of ranch mink are incidental. Mink farms in most cases are less than 10-year-old buildings provided with advanced security systems to prevent escapes of animals outside the farm (JEŻEWSKA-WITKOWSKA et al. 2014). The comparison of Polish feral animals not only with ranch individuals, as it was previously done by MiCHALSKA-PARDA et al. (2009) and ZALEWSKI et al. (2010), but also with wild mink from North America, allowed this study to avoid the overestimation of the proportion of ranch mink (understood as farm escapes) in the feral populations.

Colonization of a new area can be triggered by a single introduction of a number of individuals on the territory or can result from multiple introductions. After a certain time, populations of invasive species 
introduced into a new area generally stabilize and their numbers remain constant. However, the invasive species will eventually colonize a less favorable habitat, which indicates the need for vigilance against their potential for expansion, even if their distribution seems to be unchanged for some time (FRASER et al. 2015). The impact of escaped breeding mink on populations living in the wild is not clear. In Canada, individuals escaping from farms may have contributed to the collapse of the native populations of wild mink by introgressive hybridization and disease transmission (KIDD et al. 2009). It has also been proved that domestic mink are artificially selected for traits that are desired by mink breeders, and as such, introgression with wild mink may lead to loss of local adaptation (BOwMAN et al. 2017). Genetic monitoring can provide valuable information on temporal changes in the population of American mink, suggesting that this approach can be used to evaluate and improve programs for control of invasive vertebrates (ZALEWSKI et al. 2016). Knowledge about the genetic structure and genetic diversity of native source mink populations helps to explain these parameters also in ranch but especially in feral populations of Neovison vison.

The impact of the American mink on local ecosystems is an important problem in many European countries. Rational strategy is necessary to control the number of wild living populations of this species. Several strategies have been implemented by some countries so far: live trapping, continuous population size monitoring and eradication of the species (BONESI \& PALAZON 2007). Management strategies developed for island ecosystems are aimed at complete eradication of the species, while in continental areas management measures aimed at controlling size of the feral mink population and its constant maintenance at low level are more popular (ZABALA et al. 2010). Sometimes mixed strategies based on two different approaches are implemented. In England, management strategy includes mink trapping and systematic monitoring of mink population (HARRINGTON et al. 2009). Application of these management strategies produced diverse effects. Actions undertaken in the United Kingdom in the ' 60 s aimed at eradicating the American mink failed to produce any effect, while implementation of population monitoring and measures for reducing mink population in the ' 90 s was very successful. However, in Finland and Estonia eradication of the species was efficient and brought about desired results (BONESI \& PALAZON 2007). Initiating efforts targeted at controlling feral mink populations in Europe is justified and can be realised by adopting described strategies. However, it requires cooperation between neighbouring countries, due to possible migration of individuals. One aspect that should be taken into account in the controlling strategy is the genetic structure analysis and creation of mink genetic profiles database, with the possibility of individual genotype assignment. It should include representatives of all feral subpopulations existing in Poland, and also ranch individuals, which would help to check the origin of animals arising from the expansion of the American mink population.

\section{Acknowledgements}

This research was supported by the funds of The National Centre for Research and Development (NCBiR), development project no. 12-0140-10.

\section{References}

Anistoroaei R., Farid A., Benkel B., Cirera S. \& Christensen K. (2006). Isolation and characterization of 79 microsatellite markers from the American mink (Mustela vison). Animal Genetics 37: 179-188. https://doi.org/10.1111/j.1365-2052.2006.01429.x

Anistoroaei R., Menzorov A., Serov O., FArid A. \& Christensen K. (2007). The first linkage map of the American mink (Mustela vison). Animal Genetics 38: 384-388.

https://doi.org/10.1111/j.1365-2052.2007.01621.x 
HORECKA B., American mink genetic diversity studies

BeAuclerc K.B., Bowman J. \& Schulte-Hostedde A.I. (2013). Assessing the cryptic invasion of a domestic conspecific: American mink in their native range. Ecology and Evolution 3 (7): 2296-2309. https://doi.org/10.1002/ece3.630

BELLIVEAU A.M., FARID A., O'CONNELL M. \& WRIGHT J.M. (1999). Assessment of genetic variability in captive and wild American mink (Mustela vison) using microsatellite markers. Canadian Journal of Animal Science 79: 7-16. https://doi.org/10.4141/A97-115

BONESI L. \& PALAZON S. (2007). The American mink in Europe: Status, impacts, and control. Biological Conservation 134: 470-483. https://doi.org/10.1016/j.biocon.2006.09.006

Bowman J., Kidd A.G., Martin P.A., Mcdaniel T.V., Nituch L.A. \& Schulte-Hostedde A.I. (2012). Testing for bias in a sentinel species: contaminants in free-ranging domestic, wild, and hybrid mink. Environmental Research 112: 77-82. https://doi.org/10.1016/j.envres.2011.11.004

Bowman J., Beauclerc K., Farid A.H., Fenton H., KlÜtsch C.F.C. \& Schulte-Hostedde A.I. (2017). Hybridization of domestic mink with wild American mink (Neovison vison) in eastern Canada. Canadian Journal of Zoology 9: 443-451. https://doi.org/10.1139/cjz-2016-0171

BRZEZIŃSKI M. \& MARZEC M. (2003). The origin, dispersal and distribution of the American mink Mustela vison in Poland. Acta Theriologica 48 (4): 505-514. https://doi.org/10.1007/BF03192496

CieŚlak M., Reissmann M., Hofreiter M. \& Ludwig A. (2011). Colours of domestication. Biological Reviews 86: 885-899. https://doi.org/10.1111/j.1469-185X.2011.00177.x

CRAWFORD K.M. \& WHITNEY K.D. (2010). Population genetic diversity influences colonization success. Molecular Ecology 19 (6): 1253-1263. https://doi.org/10.1111/j.1365-294X.2010.04550.x

DLUGOSCH K.M. \& PARKER I.M. (2008). Founding events in species invasions: genetic variation, adaptive evolution, and the role of multiple introductions. Molecular Ecology 17: 431-449. https://doi.org/10.1111/j.1365-294X.2007.03538.x

EARL D.A. \& VONHOLDT B.M. (2012) STRUCTURE HARVESTER: a website and program for visualizing STRUCTURE output and implementing the Evanno method. Conservation Genetics Resources 4 (2): 359-361. https://doi.org/10.1007/s12686-011-9548-7

EVANNO G., REGNAUT S. \& GOUDET J. (2005). Detecting the number of clusters of individuals using the software STRUCTURE: a simulation study. Molecular Ecology 14: 2611-2620.

https://doi.org/10.1111/j.1365-294X.2005.02553.x

FARID A., VINCENT I.R., BENKEL B.F. \& CHRISTENSEN K. (2004). Isolation of microsatellite markers for American mink (Mustela vison). VIII International Scientific Congress in Fur Animal Production. Sept. 15-18, S-Hertogenbosch, The Netherlands. Scientifur 28 (3): 228-233.

Fleming M.A., Ostrander E.A. \& COOK J.A. (1999). Microsatellite markers for American mink (Mustela vison) and ermine (Mustela erminea). Molecular Ecology 8: 1351-1362.

https://doi.org/10.1046/j.1365-294X.1999.00701_2.x

FRANKHAM R. (2005). Resolving the genetic paradox in invasive species. Heredity 94: 385. https://doi.org/10.1038/sj.hdy.6800634

FRANKHAM R. (1996). Relationship of genetic variation to population size in wildlife. Conservation Biology 10 (6): 1500-1508. https://doi.org/10.1046/j.1523-1739.1996.10061500.x

Fraser E.J., Lambin X., Travis J.M.J., Harrington L.A., Palmer S.C.F., Bocedi G. \& MACDONALD D.W. (2015). Range expansion of an invasive species through a heterogeneous landscape - the case of American mink in Scotland. Diversity and Distributions 21: 888-900.

https://doi.org/10.1111/ddi.12303

García K., Melero Y., Palazón S., Gosálbez J. \& Castresana J. (2017). Spatial mixing of mitochondrial lineages and greater genetic diversity in some invasive populations of the American mink (Neovison vison) compared to native populations. Biological Invasions 19 (9): 2663-2673.

https://doi.org/10.1007/s10530-017-1475-4 
Hammershøj M., Pertoldi C., Asferg T., Møller T.B. \& Kristensen N.B. (2005). Danish freeranging mink populations consist mainly of farm animals: evidence from microsatellite and stable isotope analyses. Journal for Nature Conservation 13: 267-274. https://doi.org/10.1016/j.jnc.2005.03.001

Harrington L.A., Harrington A.L., MoOrhouse T., Gelling M., Bonesi L. \& MACDONALD D.W. (2009). American mink control on inland rivers in southern England: an experimental test of a model strategy. Biological Conservation 142 (4): 839-849. https://doi.org/10.1016/j.biocon.2008.12.012

HERMAN W. (1979). History of domestication of the most important species of carnivorous fur animals. Hodowca Drobnego Inwentarza 2: 8-10. [In Polish.]

JAKUBCZAK A. (2006a). Characteristics of colour varieties of ranch American mink in Poland - Part I. Hodowca Zwierzat Futerkowych 25: 10-14. [In Polish.]

JAKUBCZAK A. (2006b). Characteristics of colour varieties of ranch American mink in Poland - Part II. Hodowca Zwierząt Futerkowych 26/27: 28-33. [In Polish.]

JakubczaK A., Bugno-Poniewierska M., JeŻewsKa-WitKowska G., Horecka B. \& BuśKICMAN M. (2011). Genetic differentiation of intergeneric hybrids of Blue Frost foxes and their original forms based on microsatellite polymorphism. Annals of Animal Science 11 (2): 217-225.

JeŻewska-Witkowska G., Kujawski H., Kasperek K., Horecka B., ZoŃ A. \& PióRkowska M. (2014). Inventorization of the population size of mink, red foxes, arctic foxes, raccoon dogs and polecats kept on Polish farms. Wiadomości Zootechniczne 12 (1): 3-10. [In Polish.]

KALETA T. 1984. The relationship between fur animals farming and hunting management. Hodowca Drobnego Inwentarza 6: 10-11. [In Polish.]

KALINOWSKI S.T., TAPER M.L. \& MARShALL T.C. (2007). Revising how the computer program CERVUS accommodates genotyping error increases success in paternity assignment. Molecular Ecology 16: 1099-1106. https://doi.org/10.1111/j.1365-294X.2007.03089.x

Kidd A.G., Bowman J., LesbarRéRes D. \& Schulte-Hostedde A.I. (2009). Hybridization between escaped domestic and wild American mink (Neovison vison). Molecular Ecology 18: 1175-1186. https://doi.org/10.1111/j.1365-294X.2009.04100.x

KIMURA M. \& CROW J.F. (1964). The number of alleles that can be maintained in a finite population. Genetics 49: 725-738.

KRUSKA D.C.T. \& SCHREIBER A. (1999). Comparative morphometrical and biochemical-genetic investigations in wild and ranch mink (Mustela vison: Carnivora: Mammalia). Acta Theriologica 44 (4): 377-392.

KRUSKA D.C.T. \& SIDOROVICH V.E. (2003). Comparative allometric skull morphometrics in mink (Mustela vison Schreber, 1777) of Canadian and Belarus origin; taxonomic status. Mammalian Biology 68: 257-276. https://doi.org/10.1078/1616-5047-00095

LYNCH J.M. \& HAYDEN T.J. (1995). Genetic influences on cranial form: variation among ranch and feral American mink Mustela vison (Mammalia: Mustelidae). Biological Journal of the Linnean Society 55: 293-307. https://doi.org/10.1111/j.1095-8312.1995.tb01067.x

MARRS R.A., SFORZA R. \& Hufbauer R.A. (2008). When invasion increases population genetic structure: a study with Centaurea diffusa. Biological Invasions 10: 561-572.

https://doi.org/10.1007/s10530-007-9153-6

MichalsKa-PARdA A., BRZEZIŃSKi M., ZALEWSKi A. \& KozAKIEWicZ M. (2009). Genetic variability of feral and ranch American mink Neovison vison in Poland. Acta Theriologica 54 (1): 1-10. https://doi.org/10.1007/BF03193132

Nes N., Einarsson E.J., Lohi O. \& Jørgensen G. (1988). Beautiful Fur Animals - and their Colour Genetics. Scientifur. 
HORECKA B., American mink genetic diversity studies

Pertoldi C., Rødjajn S., Zalewski A., Demontis D., Loeschcke V. \& KJÆrsgaArd A. (2013). Population viability analysis of American mink (Neovison vison) escaped from Danish mink farms. Journal of Animal Science 91 (6): 2530-2541. https://doi.org/10.2527/jas.2012-6039

PRitchard J.K., StePhens M. \& DonNelly P. (2000). Interference of population structure using multilocus genotype data. Genetics 155: 945-959.

REYNOLDS J.C., SHORT M.J. \& LEIGH R.J. (2004). Development of population control strategies for mink Mustela vison, using floating rafts as monitors and trap sites. Biological Conservation 120: 533543. https://doi.org/10.1016/j.biocon.2004.03.026

SŁAWOŃ J. (1978). 25 years of fur farming in Poland. Mink. Hodowca Drobnego Inwentarza 10: 17-19. [In Polish.]

TAMlin A.L., Bowman J. \& HacketT D.F. (2009). Separating wild from domestic American mink Neovison vison based on skull morphometrics. Wildlife Biology 15: 266-277.

https://doi.org/10.2981/08-004

Thirstrup J.P., Pertoldi C., LARsen P.F. \& Nielsen V.H. (2014). Heterosis in the second and third generation affects litter size in a crossbreed mink (Neovison vison) population. Archives of Biological Sciences 66 (3): 1097-1103. https://doi.org/10.2298/ABS1403097T

Thirstrup J.P., Ruiz-Gonzalez A., Pujolar J.M., LARSEn P.F., Jensen J., Randi E., Zalewski A. \& PERTOLDI C. (2015). Population genetic structure in farm and feral American mink (Neovison vison) inferred from RAD sequencing-generated single nucleotide polymorphisms. Journal of Animal Science 93 (8): 3773-82. https://doi.org/10.2527/jas.2015-8996

VINCENT I.R., FARID A. \& OTIENO C.J. (2003). Variability of thirteen microsatellite markers in American mink (Mustela vison). Canadian Journal of Animal Science 83: 597-599.

https://doi.org/10.4141/A03-001

YEH F.C. \& BOYLE T.J.B. (1997). Population genetic analysis of codominant and dominant markers and quantitative traits. Belgian Journal of Botany 129: 157-163.

Zabala J., Zuberogoitia I. \& GonZÁleZ-Oreja J.A. (2010). Estimating costs and outcomes of invasive American mink (Neovison vison) management in continental areas: a framework for evidence based control and eradication. Biological Invasions 12 (9): 2999-3012.

https://doi.org/10.1007/s10530-010-9690-2

ZALEWSKI A. \& BRZEZIŃSKI M. (2014). American Mink. Biology of Invasive Species. Instytut Biologii Ssaków PAN, Białowieża.

Zalewski A., Michalska-Parda A., BARToszewicz M., KozAKiewicz M. \& BrZeziŃSKi M. (2010). Multiple introductions determine the genetic structure of an invasive species population: American mink Neovison vison in Poland. Biological Conservation 143: 1355-1363.

https://doi.org/10.1016/j.biocon.2010.03.009

ZALEwski A., ZALEwSKA H., LunNeryd S.G., ANDRÉ C. \& MikusińSKi G. (2016). Reduced genetic diversity and increased structure in American mink on the Swedish coast following invasive species control. PLoS ONE 11 (6): e0157972: 1-23. https://doi.org/10.1371/journal.pone.0157972

Manuscript received: 31 July 2018

Manuscript accepted: 20 March 2019

Published on: 30 April 2019

Branch editor: Peter Galbusera 


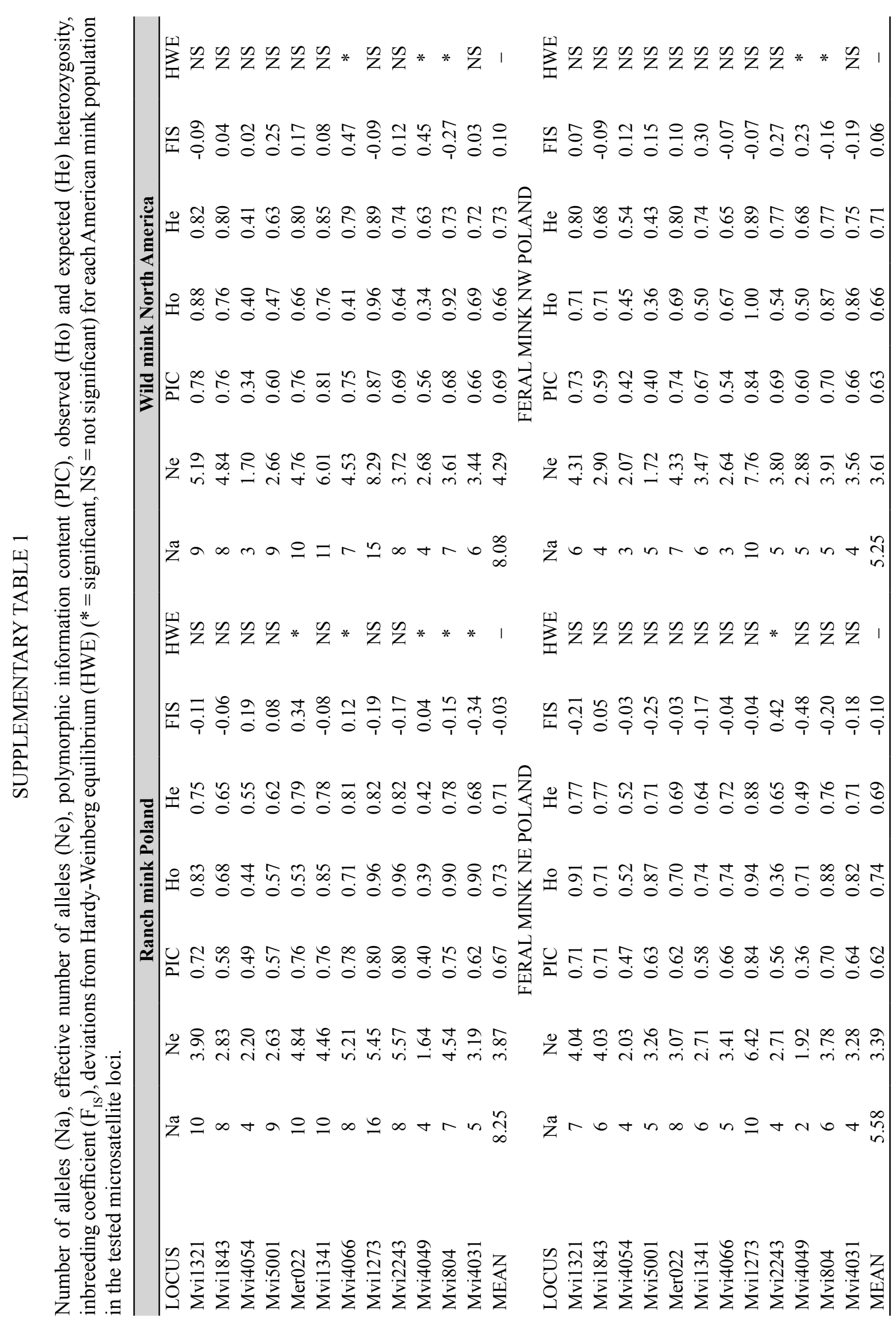


HORECKA B., American mink genetic diversity studies

\section{SUPPLEMENTARY TABLE 2}

Results of Evanno $\triangle \mathrm{K}$ estimation method obtained with STRUCTUR HARVESTER for $\mathrm{K}$ values from 3 to 10 . The highest value of $\Delta K$ parameter for $K=5$ is indicated in bold.

\begin{tabular}{ccccccc}
\hline K & Reps & Mean LnP(K) & Stdev LnP(K) & Ln'(K) & $\mid \mathbf{L n ” ( K ) |}$ & Delta K \\
\hline 3 & 20 & -6762.790000 & 3.585336 & - & - & - \\
4 & 20 & -6722.870000 & 81.237748 & 39.920000 & 24.710000 & 0.304169 \\
5 & 20 & -6658.240000 & 31.728675 & 64.630000 & 92.405000 & 2.912350 \\
6 & 20 & -6686.015000 & 92.968310 & -27.775000 & 134.165000 & 1.443126 \\
7 & 20 & -6847.955000 & 453.961867 & -161.940000 & 277.170000 & 0.610558 \\
8 & 20 & -6732.725000 & 110.377161 & 115.230000 & 229.385000 & 2.078193 \\
9 & 20 & -6846.880000 & 231.070346 & -114.155000 & 124.540000 & 0.538970 \\
10 & 20 & -7085.575000 & 484.588847 & -238.695000 & - & - \\
\hline
\end{tabular}

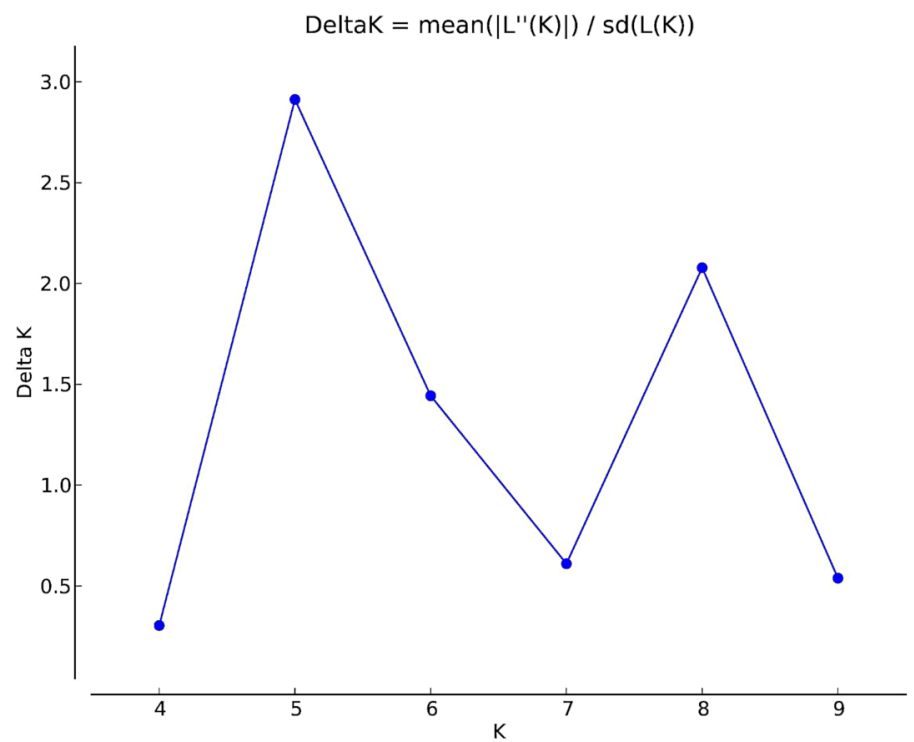

Supplementary Fig. 1 - Graphical interpretation of the results of Evanno $\Delta \mathrm{K}$ method showing a clear peak at the $\mathrm{K}$ value of 5 . 